\title{
Influence of wood density in tree-ring-based annual productivity assessments and its errors in Norway spruce
}

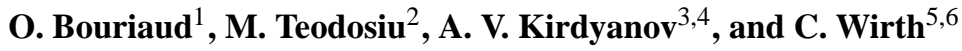 \\ ${ }^{1}$ National Research and Development Institute for Forestry, National Forest Inventory, Calea Bucovinei 73b, 725100 \\ Câmpulung Moldovenesc, Romania \\ ${ }^{2}$ National Research and Development Institute for Forestry, Calea Bucovinei 73b, 725100 Câmpulung Moldovenesc, Romania \\ ${ }^{3}$ V.N. Sukachev Institute of Forest SB RAS, Akademgorodok, Krasnoyarsk, 660036, Russia \\ ${ }^{4}$ Siberian Federal University, Krasnoyarsk, 660041, Russia \\ ${ }^{5}$ Institute of Biology, University of Leipzig, Johannisallee 21-23, 04103 Leipzig, Germany \\ ${ }^{6}$ German Centre for Integrative Biodiversity Research (iDiv) Halle-Jena-Leipzig, Deutscher Platz 5e, 04103 Leipzig, \\ Germany
}

Correspondence to: O. Bouriaud (obouriaud@gmail.com)

Received: 14 March 2015 - Published in Biogeosciences Discuss.: 22 April 2015

Revised: 4 August 2015 - Accepted: 6 October 2015 - Published: 29 October 2015

\begin{abstract}
Estimations of tree annual biomass increments are used by a variety of studies related to forest productivity or carbon fluxes. Biomass increment estimations can be easily obtained from diameter surveys or historical diameter reconstructions based on tree rings' records. However, the biomass models rely on the assumption that wood density is constant. Converting volume increment into biomass also requires assumptions about the wood density. Wood density has been largely reported to vary both in time and between trees. In Norway spruce, wood density is known to increase with decreasing ring width. This could lead to underestimating the biomass or carbon deposition in bad years. The variations between trees of wood density have never been discussed but could also contribute to deviations. A modelling approach could attenuate these effects but will also generate errors.

Here a model of wood density variations in Norway spruce, and an allometric model of volume growth were developed. We accounted for variations in wood density both between years and between trees, based on specific measurements. We compared the effects of neglecting each variation source on the estimations of annual biomass increment. We also assessed the errors of the biomass increment predictions at tree level, and of the annual productivity at plot level.

Our results showed a partial compensation of the decrease in ring width in bad years by the increase in wood density. The underestimation of the biomass increment in those years
\end{abstract}

reached $15 \%$. The errors related to the use of an allometric model of volume growth were modest, around $\pm 15 \%$. The errors related to variations in wood density were much larger, the biggest component being the inter-tree variability. The errors in plot-level annual biomass productivity reached up to $40 \%$, with a full account of all the error sources.

\section{Introduction}

Predicting trees' biomass increment is a key step in quantifying and understanding forest productivity. Considerable efforts have been spent in evaluating forest productivity and carbon sink strength (Ciais et al., 2008). While productivity has long referred to volume growth, amply used in the forest management and displayed in yield tables, the focus has recently switched to biomass, for its relationships with energy or carbon storage. Field-based estimations of biomass growth have a wide variety of applications, from forestry to carbon fluxes estimation, for example in comparison against eddy covariance (Barford et al., 2001; Rocha et al., 2006; Gough et al., 2008; Curtis et al., 2002; Ilvesniemi et al., 2009). Considerable efforts have been spent in estimating annual forest productivity in relation to climate fluctuations and forests' carbon sink strength (Richardson et al., 2010; Wu et al., 2014). The importance of having both annual resolution 
and high spatial coverage has been illustrated by numerous studies (e.g. Reichstein et al., 2007; Ciais et al., 2005; Beer et al., 2010). Several methods are used to estimate forest productivity and carbon sink: eddy covariance, modelling, or field-based estimations such as inventories or tree-ring studies. Tree-ring-based studies have the advantage of offering a large spatial covering, a potentially long timescale and also an annual resolution. They are therefore often used to produce reference annual biomass production estimations, to compare with other methods (Beck et al., 2011; Babst et al., 2014a) or to provide complementary information (Babst et al., 2013). However, several issues are associated with the use of tree-ring-based estimations and the estimation of their error remains a critical issue that is poorly documented (Nickless et al., 2011).

In the reconstruction of the annual productivity or of the above-ground carbon uptake from field-based studies, one limiting element is the estimation of the wood density variations (Babst et al., 2014a). Indeed, volume increment time series can be produced by a variety of methods, such as the reconstruction of the diameter growth, based on tree rings (Wirth et al., 2004; Rocha et al., 2006) or inventory reconstruction (Ohtsuka et al., 2007), but none of these methods provide information on the variation of wood density. Converting volume into biomass requires an estimation of the wood density, which is most likely based on literature and therefore related neither to site conditions, nor to trees' growth rate, as for example in Vilàet al. (2013). In the same manner, biomass equations implicitly rely on the use of an average and constant wood density despite the many evidences of substantial wood density variations. In both cases, wood density is considered constant in time, and equal between trees.

Wood density has however been acknowledged as a highly variable characteristic, and several major sources of annual density variations have been identified. Very high precision in the description of the wood density variations with new techniques (e.g. SilviScan; Evans, 1994) is possible but not widely available, while other techniques based on Xray are rather time-consuming and thus not applied to forest productivity studies. Within-tree variations occur at distinct timescales (Jyske et al., 2008). Over medium or long timescales, annual wood density was proved to be related to ring age or to tree diameter, with higher values close to the pith in many species (Schweingruber, 1988). At an interannual scale, wood density variations can be substantial. There were several reports that (annual) ring density decreases with increasing ring width, for instance in Norway spruce (Bergqvist, 1998; Dutilleul et al., 1998; Lundgren, 2004; Bouriaud et al., 2005; Franceschini et al., 2010, 2013). Wood density was also proved to vary between trees (Wilhelmsson et al., 2002; Guilley et al., 2004), a fact which is never accounted for in studies using diameter surveys to produce biomass increment estimations.
The variations in wood density between trees and between years could compensate the variations in annual volume increment, or at least soften them. Recent studies have brought evidence of such compensation, proving that neglecting annual wood density fluctuations could lead to substantial errors or bias in estimating the biomass (Molto et al., 2013; Babst et al., 2014a). The errors generated by neglecting the variations in wood density have been considered small compared to those resulting from the volume increment estimation, but to our knowledge, such assumptions have never been tested and the consequences not documented.

To be properly quantified, the consequences of neglecting wood density fluctuations between years and between trees had to be tested using an integrated approach, whereby the errors of the density model are propagated and combined with those of the model for volume growth. Such chains can be decomposed, and the impact of each step was studied by modelling the steps into a single Markov chain Monte Carlo (MCMC) process (e.g. Molto et al., 2013). Analytical solutions to estimate the biomass estimation error, based e.g. on Taylor expansion can sometimes be determined, depending on the model's complexity. But the errors of biomass increment, obtained by subtracting subsequent estimations, are anyhow less predictable and particularly challenging at the plot level, when summing tree-level estimations (Nickless et al., 2011). The MCMC approach therefore appears to be the most suitable to estimate the biomass increment, where such estimations and the propagation of the errors from one model to another are done without assumptions.

Our study aimed to quantify the impact of density variations, both between years and between trees, on the estimations of annual biomass increment in Norway spruce (Picea abies), and compare it with the impact of volume increment estimation errors. The objectives were as follows: (i) to quantify and model the influence of annual radial growth variations on wood density, (ii) to quantify the consequences of annual and between-tree variations of wood density on biomass increment estimations, and (iii) to compare the errors related to wood density estimations to those of volume increment.

\section{Material and methods}

\subsection{Site, sampling and data}

All samples analysed for this study were taken from the Wetzstein site near the village of Lehesten in Thuringia, central Germany ( $50^{\circ} 45^{\prime} \mathrm{N}, 11^{\circ} 46^{\prime} \mathrm{E} ; \sim 760 \mathrm{~m}$ a.s.l.), which was amply used for eddy covariance measurements (e.g. Anthoni et al., 2004) or biomass modelling (Wirth et al., 2004). The site is characterized by mono-specific Norway spruce (Picea abies L.) stands. The climate is typical for the mid-elevation montane sites, with an annual mean temperature of $6{ }^{\circ} \mathrm{C}$ and a mean annual precipitation sum of $\sim 1000 \mathrm{~mm}$. Soils have 
a sandy loam texture. The footprint of the eddy covariance tower is dominated by an extensive $80( \pm 2.1 \mathrm{SD})$ year old stand. This stand is mostly even-aged but also contains pockets of regeneration and scattered emergent trees. The footprint stand is surrounded by three even-aged stands with a mean age of $15( \pm 0.86), 38( \pm 7.9)$, and $116( \pm 1.3)$ years. The four stands representing the site are referred to as W15, W38, W72, and W116.

This study combines data from three successive samplings realized in this site: (i) stem analysis performed to quantify the relationship between breast-height radial growth and stem volume increment. This was achieved in connection with a biomass harvest of the four stands (see below); (ii) wood density measurements taken for selected harvest trees to establish a relation between ring-width and wood density variations; and (iii) a dendrochronological analysis of interannual growth variation of many trees carried out using micro-cores for scaling up to the plot scale. The volume increment and wood density measurements are used exclusively to develop models, while the micro-core sampling is used as an application to quantify and compare the errors of each model in this representative case study.

\subsubsection{Stem analysis for volume increment}

The stem volume increment model was fit based on a stem analysis realized on 22 trees - seven samples in the footprint stand W72 and five in each of the additional stands (W15, W33, W116). Trees were selected to represent seven/five DBH (diameter at breast height) classes, defined based on the population of all inventoried trees (W15: $n=144$, W38: $n=59$, W72: $n=133$, W116: $n=68$ ). Jointly, the 22 trees represented the size range (DBH between 7.3 and $59.5 \mathrm{~cm}$ ) and age range (between 14 and 117 years) of Norway spruce trees at the Wetzstein site (see also Supplement Table S1). This comprehensiveness ensures applicability of the models for all trees in the inventories of the test site. Trees were felled in the context of a full biomass harvest. The circumference was measured every metre along the bole where a $3-8 \mathrm{~cm}$ thick disc was cut in order to determine annual increment along the entire stem. All discs were dried and sanded with a belt grinder. The ring-width series were measured along four radii on each disc. The average diameter increment measured on the lower and upper disc of each 1 to $2 \mathrm{~m}$ segment was used to calculate the increment of under bark volume in successive years using the formula for a truncated cone. The difference in volumes of all segments per tree of successive annual time steps yielded stem dry wood production of individual trees. The dendrochronological analysis was carried out using a digital tree ring measurement device (LINTAB III Digital Linear Table; 410-1/100-HF-130, Frank Rinn Distribution, Heidelberg, Germany) in combination with the software TSAP (Time Series Analysis Program, Frank Rinn Distribution, Heidelberg, Germany).

\subsubsection{Wood density measurements}

For the annual wood density (WD) measurements, wood discs were sampled at breast height from trees, representing the lowest, the central, and the highest diameter class in each of the four stands. This yielded a total of 12 sample trees, again representing the size and age range of Norway spruce trees at the site. Two 1-2 cm wide slices from opposite radii were sawn from the wood discs, for which wood density was measured by X-ray densitometry in the densitometric laboratory of Krasnoyarsk, Russia (Walesch Electronics, Switzerland), using the standard procedure described by Schweingruber (1988). Longitudinal strips with a constant thickness of $1.2 \mathrm{~mm}$ were sawn, air dried, and exposed to X-ray radiation for $1 \mathrm{~h}$ on a Kodak TL film using standard exposure conditions: acceleration tension of $8.5 \mathrm{kV}$, flux intensity of $15.0 \mathrm{~mA}$, and a distance to the source of $3.5 \mathrm{~m}$. Annual wood density (WD, $\mathrm{kg} \mathrm{m}^{-3}$ ) values were obtained from density profiles of single tree rings as the total mass of earlywood and latewood divided by tree-ring width. Xray-derived densities represent dry wood. Rescaling to fresh wood dimensions was not done as all ring-width series (stem analysis and micro-cores) were measured on dry wood.

\subsubsection{Application data set}

The volume increment and WD models were applied together on an independent set of trees sampled in 13 randomly placed inventory plots inside the footprint stand W72. The plots were established within the context of the project FORCAST (Rey and Jarvis, 2006). Thirty-one to 62 trees per plots (551 in total) with diameter varying from 8 to $51 \mathrm{~cm}$ (thus well within the range of the sample trees) were sampled for historical diameter reconstruction based on micro-cores. The micro-cores enabled the reconstruction of the past growth over the last 10 years only, since these short cores are $\sim 2 \mathrm{~cm}$ long. The diameter was reconstructed based on the simple assumption about proportionality of the bark thickness to the diameter using the external diameter of the trees at sampling.

\subsection{Wood density and annual volume increment modelling}

Models of WD or annual volume increment were fit using both maximum likelihood methods and the MCMC approach. The structure of the two models was first determined using likelihood fits before being implemented in a Bayesian MCMC framework using WinBUGS 1.4 (Spiegelhalter et al., 2003), based on exactly the same data sets, using noninformative flat priors. The maximum-likelihood estimations were realized using the "nlme" package (version 3.1-102, Pinheiro et al., 2011) of R (R version 3.0.1, R Development Team, 2014). 


\subsubsection{The wood density model}

Following recent publications on Norway spruce wood density (Franceschini et al., 2010, 2013), the diameter and the ring cambial age (as counted from the pith) were used as independent variables. The selection of the model was based both on the AIC (Akaike information criterion) and the examination of the residual distribution. Fixed and random treelevel effects were considered. The principle of parsimony was also followed in the model-building process, and random effect parameters were considered only if improvements were observed based on the likelihood ratio test.

Several candidate models were tested, as follows:

$$
\begin{aligned}
& \mathrm{WD}_{i j}=a_{0}+a_{1} \mathrm{RW}_{i j}+a_{2} \mathrm{RW}_{i j}^{2}+\frac{a_{3}}{X_{i j}}+\varepsilon_{i j} \\
& \mathrm{WD}_{i j}=a_{0}+\frac{a_{1}}{1+\mathrm{RW}_{i j}}+\frac{a_{2}}{X_{i j}^{a_{3}}}+\varepsilon_{i j} \\
& \mathrm{WD}_{i j}=a_{0}+a_{1} \mathrm{RW}_{i j}^{a_{2}}+\frac{a_{3}}{X_{i j}^{a_{4}}}+\varepsilon_{i j}
\end{aligned}
$$

where $i$ denotes the tree and $j$ the year; $a_{0} \ldots a_{4}$ are fixed effects and potentially random tree-level effects, $X$ is either DBH or cambial age, $\varepsilon \approx \mathrm{N}\left(0, \sigma^{2}\right)$. Random effects are assumed to be normally distributed.

\subsubsection{The annual volume increment model}

The annual volume increment was modelled as a non-linear function of ring width and tree diameter, based on the annual estimations of volume growth resulting from the detailed stem analysis. The model reflects the fact that, for a given ring width, volume increment depends strongly on the current size of the tree, here its diameter, mostly for geometrical reasons. The taper was therefore not supposed to be constant in time, and the trends in tree growth with age were directly absorbed in the model since the volume increments resulted directly from the stem analysis measurements, not from using models. Another specificity of this model was the specification of a variance function in order to cope with the heteroscedasticity in the errors. The resulting model is given in Eq. (4) and includes random coefficients for the exponent $b_{3}$ :

$$
\Delta \mathrm{Vol}_{i j}=b_{0}+b_{1} \mathrm{DBH}_{i j}^{b_{2}} \mathrm{RW}_{i j}^{b_{3}}+\varepsilon_{i j}
$$

where $b_{3, i}=c_{3}+d_{3, i}$ is the sum of a fixed parameter $c_{3}$ and a random tree-level term $d_{3, i} \sim N\left(0, \sigma_{d 3}\right)$ that varied for each tree $i$.

The residual $\varepsilon_{i j}$ was modelled as a power function of the diameter:

$\varepsilon_{i j}=b_{4}+\mathrm{DBH}^{b_{5}}$

\subsection{Application to a case study, scenarios of biomass increment}

The micro-core data set was used as a concrete case study for estimating the consequences of wood density variations and comparing the errors resulting from the wood density and from the volume increment model. Both models were fit based on their specific data sets within the MCMC framework (code provided in Supplement S2); then the estimated parameters and the variance terms were applied to compute the biomass increment of the micro-cores trees, which represents an external set. The models were therefore fit using the same structure as that used in the likelihood method, the estimated parameters being further used to produce estimations of WD or annual volume increment on the micro-core trees. Having both the fitting and the application run in a single MCMC loop enables the propagation of the errors of each model.

The tree-level biomass increment estimations were the product of the WD and the volume increment, then summed up to obtain stand level per hectare biomass estimations, also based on the plot size. But according to the way the errors could be accounted for, four different scenarios were distinguished:

1. In the baseline scenario ( $\mathrm{sc} 1$ ), a constant wood density was used, set to be equal to the average observed value across the data set $\left(475 \mathrm{~kg} \mathrm{~m}^{-3}\right)$. The volume increment is estimated based on the model fitted but without considering random tree-level variations (using the fixed part of the model only) and without residual error $\left(\varepsilon_{i j}=0\right)$. Thus, for tree $i$ and year $j$, the biomass increment was computed as

$$
\Delta B_{i j}=0.475 \cdot \Delta \operatorname{Vol}_{i j}, \text { where } \Delta \operatorname{Vol}_{i j}=b_{0}+b_{1} \mathrm{DBH}_{i j}^{b_{2}} \mathrm{RW}_{i j}^{b_{3}} .
$$

Only the fixed part of the parameters $b_{0}$ to $b_{3}$ was used.

2. In the second scenario ( $\mathrm{sc} 2)$, the annual wood density was held constant but the volume increment included both the random tree-level variation and the residual error.

For tree $i$ and year $j$, the biomass increment was computed as

$$
\begin{aligned}
& \Delta B_{i j}=0.475 \cdot \Delta \mathrm{Vol}_{i j} \text { with } \\
& \Delta \mathrm{Vol}_{i j}=b_{0}+b_{1} \mathrm{DBH}_{i j}^{b_{2}} \mathrm{RW}_{i j}^{b_{3, i}}+\varepsilon_{i j},
\end{aligned}
$$

where $b_{3, i}=c_{3}+d_{3, i}$ is the sum of a fixed parameter $c_{3}$ and a random tree-level term that varied for each tree $i$ and sampled as $d_{3, i} \sim N\left(0, \sigma_{d 3}\right), \sigma_{d 3}$, estimated from the volume increment fit data set. Thus, the parameter $d_{3}$ for the application varies from tree to tree and is being sampled from within the variability observed in the 
fit set. $\varepsilon$ (the residual variation) is computed as a function of the diameter as presented in Eq. (5). All the parameters and the variance estimations were made by the Bayesian model within the MCMC loop.

3. In the third scenario ( $\mathrm{sc} 3$ ), the biomass increment was defined as the product of the parametric estimations of both the WD and the annual volume increment: here only the fixed part of the models was used to produce both the WD and the volume increment estimations, while not accounting for random effects or residual variance. This represents the most common and probable use of such models, when no data are available for a calibration.

$$
\begin{aligned}
& \Delta B_{i j}=\mathrm{WD}_{i j} \cdot \Delta \mathrm{Vol}_{i j}, \quad \text { where } \\
& \mathrm{WD}_{i j}=a_{0}+a_{1} \mathrm{RW}_{i j}^{0.5}+\frac{a_{2}}{\mathrm{DBH}_{i j}^{0.5}} \quad \text { and } \\
& \Delta \mathrm{Vol}_{i j}=b_{0}+b_{1} \mathrm{DBH}_{i j}^{b_{2}} \mathrm{RW}_{i j}^{b_{3}} .
\end{aligned}
$$

Only the fixed part of the parameters was used.

4. In the last scenario ( $\mathrm{sc} 4)$, a full error propagation was conducted: the random and the residual errors of both the WD and the volume increment models were used to produce the biomass increment estimation.

$$
\begin{aligned}
\Delta B_{i j} & =\mathrm{WD}_{i j} \cdot \Delta \mathrm{Vol}_{i j} \quad \text { with } \\
\mathrm{WD}_{i j} & =a_{0, i}+a_{1, i} \mathrm{RW}_{i j}^{a_{2}}+\frac{a_{3, i}}{\mathrm{DBH}_{i j}^{a_{4}}}+\varepsilon_{i j},
\end{aligned}
$$

having $\forall k \in[1,3], a_{k, i}=\alpha_{k}+a_{k, i}$ where $\alpha_{k}$ is the fixed part of the parameter, $a_{k}$ the random component, $a_{k, i} \sim N\left(0, \sigma_{a k}\right)$, and $\varepsilon_{i i} \sim N\left(0, \sigma_{\mathrm{WD}}\right)$, where $\sigma_{\mathrm{WD}}$ is the residual variance, estimated on the WD fit set.

$\Delta \operatorname{Vol}_{i j}=b_{0}+b_{1} \mathrm{DBH}_{i j}^{b_{2}} \mathrm{RW}_{i j}^{b_{3, i}}+\varepsilon_{i j}$ with $b_{3, i}=c_{3}+$ $d_{3, i}$ and $d_{3, i} \sim N\left(0, \sigma_{d 3}\right)$ as in scenario 2 , and $\varepsilon_{i i} \sim$ $N\left(0, \sigma_{\Delta} \mathrm{Vol}\right)$, where $\sigma_{\Delta}$ Vol is the residual variance, estimated from the volume increment fit set.

Thus, four different biomass increment estimations were produced, according to the density estimation and the error propagation, and their difference was summed at plot level. In all the scenarios, volume increment was estimated based on measured ring-width series and the historical diameter of the trees.

The MCMC process generated posterior distributions of the model parameter estimates, with their associated errors, and the estimations of the variance of the random effects, based on the Metropolis-Hastings algorithm over $10^{4}$ iterations. It also produced estimations of wood density, a volume increment computed from the fitted model and applied to new data, along with a prediction uncertainty interval, here represented by the range between 2.5 and $97.5 \%$ of the estimates' distribution density. The first 4000 iterations were used as pre-convergence and thus were excluded from estimations, which were based on subsequent iterations only.
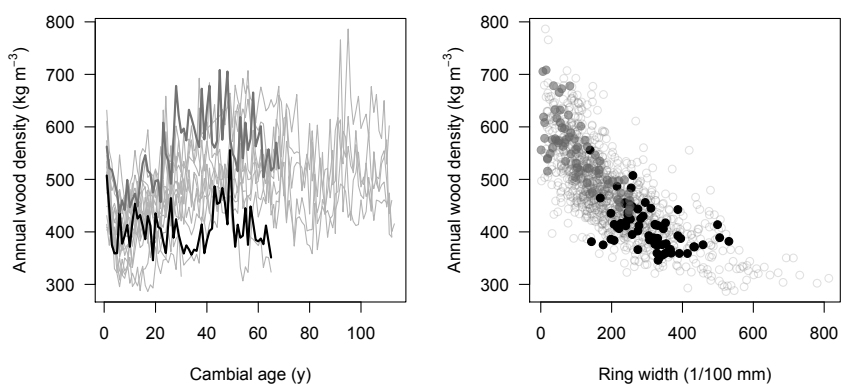

Figure 1. Relation between annual wood density and cambial age (left) or ring width (right) at tree level. Two trees with very distinct average wood density were highlighted (dark grey/black).

\section{Results}

\subsection{Describing wood density variability}

The (annual) ring wood density (WD) varied from 287 to $787 \mathrm{~kg} \mathrm{~m}^{-3}$ with within-trees variations as considerable as variations between trees. Individual tree-ring series showed a reduced WD in the first 5-10 years, followed by a linear increase up to 60 years and then fluctuated around a treespecific sill (Fig. 1a). Variations difference between two successive years reached $200 \mathrm{~kg} \mathrm{~m}^{-3}$.

Variations in WD were mostly related to ring width with a linear correlation of $-0.75(t=-39.23, \mathrm{~d} f=1199$, $p$ value $<10^{-4}$ ) when pooling the data from all cores (Fig. 1b). As shown in Fig. 1, WD series with very distinct average density values seemingly followed the same linear pattern. The correlation with age was not as high $\left(R_{\text {Pearson }}=0.38, t=14.25, \mathrm{~d} f=1199, p\right.$ value $\left.<10^{-4}\right)$.

\subsection{Modelling annual wood density variability}

The selection of the WD model resulted from the comparison of several models based on independent variables such as ring width, cambial age, and diameter. The models of fered very comparable results (Table 1) although model 2 had a greater root-mean-square error (RMSE) and bias. Using cambial age or diameter as a second independent variable did not lead to significant differences in the fit according to the likelihood ratio test (LRT). Nevertheless, models differed in the ease of the convergence or in the sensitivity to initial parameters provided. The exponent parameters $a_{2}$ and $a_{4}$ of the independent variables (RW and $X$ ) were close to 0.5 in model 3; a simplification was tested which enabled to reduce the number of parameters and considerably eased the fitting, whereby both exponents were fixed to 0.5 . This simplification did not lead to a significant change in the AIC. The model retained was therefore model 4 derived from Eq. (3) with exponent parameters set to 0.5 , and with the DBH as a second independent variable, which is also a variable easier to measure than the cambial age. 
Table 1. Fit statistics and parameters for the wood density models.

\begin{tabular}{llllllr}
\hline Eq. & Model & Fixed effect & $\mathrm{d} f$ & AIC & $\begin{array}{r}\text { RMSE } \\
\mathrm{kg} \mathrm{m}^{-3}\end{array}$ & $\begin{array}{r}\text { Bias } \\
\mathrm{kg} \mathrm{m}^{-3}\end{array}$ \\
\hline 1 & $\mathrm{WD}=a_{0}+a_{1} \mathrm{RW}+a_{2} \mathrm{RW}^{2}+a_{3} / X^{0.5}$ & $\mathrm{RW}, \mathrm{CBA}$ & 12 & 12549 & 44.62 & 0.135 \\
& & $\mathrm{RW}, \mathrm{DBH}$ & 12 & 12567 & 44.90 & 0.135 \\
2 & $\mathrm{WD}=a_{0}+a_{1} /(1+\mathrm{RW})+a_{2} / X^{0.5}$ & $\mathrm{RW}, \mathrm{CBA}$ & 11 & 12770 & 60.24 & 0.874 \\
& & $\mathrm{RW}, \mathrm{DBH}$ & 11 & 12802 & 64.70 & 0.674 \\
3 & $\mathrm{WD}=a_{0}+a_{1} \mathrm{RW}^{a 2}+a_{3} / X^{a 4}$ & $\mathrm{RW}, \mathrm{CBA}$ & 12 & 12554 & 44.90 & 0.018 \\
& & $\mathrm{RW}, \mathrm{DBH}$ & 12 & 12569 & 45.15 & -0.046 \\
4 & $\mathrm{WD}=a_{0}+a_{1} \mathrm{RW}^{0.5}+a_{2} / X^{0.5}$ & $\mathrm{RW}, \mathrm{CBA}$ & 11 & 12552 & 44.92 & -0.019 \\
& & $\mathrm{RW}, \mathrm{DBH}$ & 11 & 12567 & 45.20 & -0.073 \\
\hline
\end{tabular}

WD: (annual) wood density, RW: (annual) ring width, $X$ : either cambial age (CBA) or diameter (DBH). Models 1 to 3 correspond to Eqs. (1-3) presented in Sect. 2.2.1, and model 4 corresponds to Eq. (3) with parameter $a_{2}$ and $a_{4}$ set to 0.5. There were 1201 observations in 10 groups.

\subsection{Modelling the annual volume increment}

The volume increment model was fit as a function of diameter and ring width, with fixed and random tree-level effects, to a set of 22 trees. The intercept was kept free after testing its significance using the LRT by comparing models with intercept held constant or forced to 0. It appeared that a free intercept increases the likelihood, while the estimated value of the intercept was very realistic. The use of a weight function (constant plus power) was also amply confirmed by the LRT (L.ratio $=1368, p<0.0001)$. Thus, the final model consisted of a function of diameter and ring width, with fixed and random (tree level) weighting parameters (Table 2). The adequacy of the model was confirmed by the standardized residuals plot (Fig. 2).

\subsection{The compensation problem: WD buffers annual volume increment variations}

Provided that there was an overall decrease in wood density with increasing ring width, a compensation of ring-width annual variability by wood density was also probable. The ring-width series showed peak years of growth (e.g. 1967, $1989)$ or depressions $(1976,1983)$. In these years, the radial growth was much more affected than the wood density, as suggested by the deviations relative to the mean value calculated over the entire series length. The deviations peaked in 1967 at $+30 \pm 12 \%$ ( \pm standard error), which means a radial growth greater than average by $30 \%$, while the reduction of density was only $-5 \pm 2 \%$. In 1976 , the growth reduction was $-30 \pm 6 \%$ but the density did not significantly increase: $+1 \pm 2 \%$. The consequences for biomass increment of neglecting the annual WD variations is further shown in Fig. 3 where the biomass increment was estimated for the trees included in WD measurements. The annual volume increment was estimated by applying the fitted model (Eq. 4), multiplied by either the annual WD values or by the mean WD for each tree and radius. The deviation between the two estimates is expressed as a percentage of the annual biomass

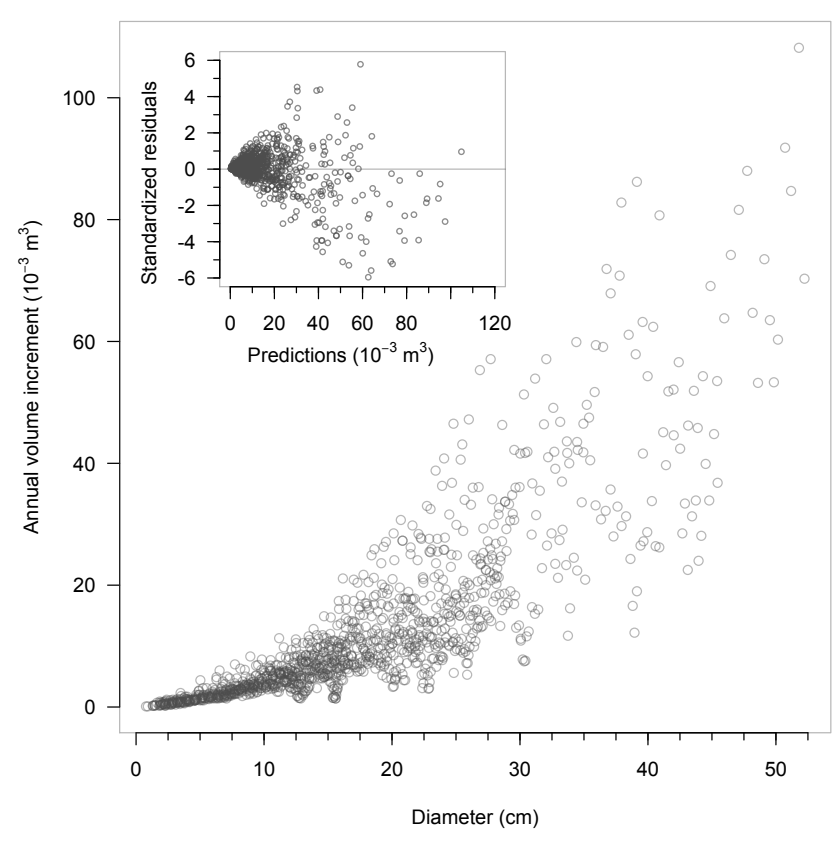

Figure 2. Observed and fitted annual volume increment model and standardized residuals of the volume increment model fit.

increment using annual WD values. Although the deviations seemed random (Fig. 3a), their ordination in time proved that they were not, and that they exceeded $15 \%$ on average among all trees during extreme years (Fig. $3 b$ ).

\subsection{Application to an independent data set}

The two models presented and fitted above were introduced in the Bayesian framework, with the same structure exactly and on the same data, and further re-fitted using the MCMC method. A comparison of the parameters estimated by both methods is presented in Table 2. Expectedly, the parameters were not exactly the same but very close, and the correlation between the predictions was very high. 
Table 2. Comparison of the fixed parameters estimated for the wood density and the volume models, obtained by maximum likelihood and MCMC. Standard deviations are provided in brackets.

\begin{tabular}{llrr}
\hline Model & Parameters & Likelihood fit & MCMC fit \\
\hline $\mathrm{WD}=a_{0}+a_{1} \mathrm{RW}^{0.5}+a_{2} / \mathrm{DBH}^{0.5}+e$ & $a_{0}$ & $594.33(16.11)$ & $555.10(20.04)$ \\
& $a_{1}$ & $-10.09(0.43)$ & $-9.23(0.70)$ \\
& $a_{2}$ & $13.93(41.21)$ & $17.13(29.00)$ \\
$\Delta V=b_{0}+b_{1} \mathrm{DBH}^{b 2} \mathrm{RW}^{b 3}+e$ & $\mathrm{e}$ & 2054 & $2083(93)$ \\
& $b_{0}$ & $0.284(0.041)$ & $0.047(0.005)$ \\
& $b_{1}$ & $0.161(0.012)$ & $0.009(0.001)$ \\
& $b_{2}$ & $1.820(0.034)$ & $1.733(0.011)$ \\
& $b_{3}$ & $0.645(0.019)$ & $0.649(0.019)$ \\
& $e=b_{4}+\mathrm{DBH}^{b 5}$ & $9.316 \mathrm{e}-03$ & $0.283(0.136)$ \\
& $b_{4}$ & 15.505 & $-0.093(0.009)$ \\
& $b_{5}$ & 1.871 & $0.225(0.005)$ \\
\hline
\end{tabular}

WD: (annual) wood density; RW: (annual) ring width; DBH: (annual) breast-height diameter; $e$ : residual error.
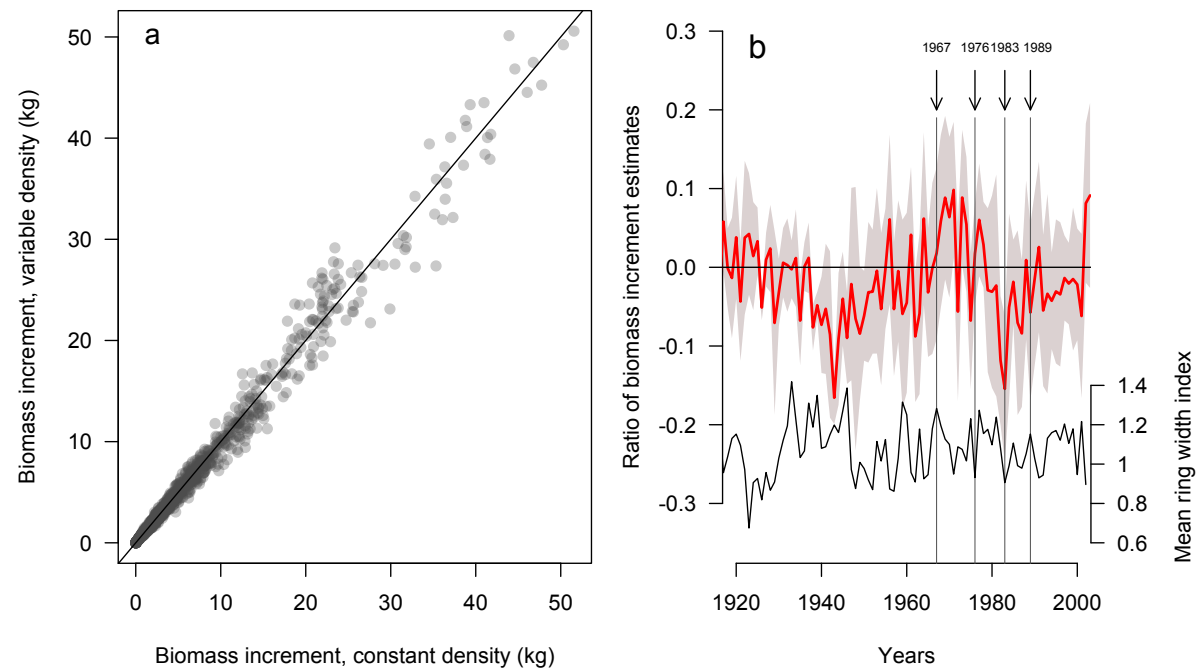

Figure 3. Left, comparison of biomass increment estimations for Norway spruce trees growing in Wetzstein, based on constant density hypothesis vs. actual wood density measurements; right, time course of the average ratio of biomass increment estimations (actual over constant density) and time course of the detrended mean ring width (spline smoothing, for illustration purposes). The $\pm 2 \mathrm{SD}$ interval for the average biomass ratio is displayed as a grey band.

When applied on the independent application set, the estimated wood density varied from 278 to $541 \mathrm{~kg} \mathrm{~m}^{-3}$, with a mean of $425( \pm 35) \mathrm{kg} \mathrm{m}^{-3}$ as a result of the variable ringwidth and diameter input values. The model reproduced large between-tree differences for a given year, up to $225 \mathrm{~kg} \mathrm{~m}^{-3}$. Including random effects did not affect the prediction mean (Fig. 4). The overall (pooling trees from all plots together) average difference between the two predictions was only $0.1 \mathrm{~kg} \mathrm{~m}^{-3}$. The inclusion of the random effects changed the predictions only very marginally but increased the prediction interval 5 times: it jumped from $\pm 20-40$ to $\pm 160 \mathrm{~kg} \mathrm{~m}^{-3}$. Accounting for the residual variation (the epsilon term in Eq. 3) increased the prediction interval only slightly: it added an extra $\pm 10 \mathrm{~kg} \mathrm{~m}^{-3}$.
Comparable results were obtained with the volume increment model: the contribution of the random effects and the inclusion of the residual variance inflated the prediction interval substantially (Fig. 4). Nevertheless, the relative prediction interval was substantially lower than that of the wood density: typically less than $40 \%$ of the predicted value, compared to $60 \%$ for WD.

\subsection{Consequences of WD variations and error sources for the biomass increment estimations}

\subsubsection{At tree level}

The annual variations of the predicted biomass increment resulting from considering a dynamic wood density were 

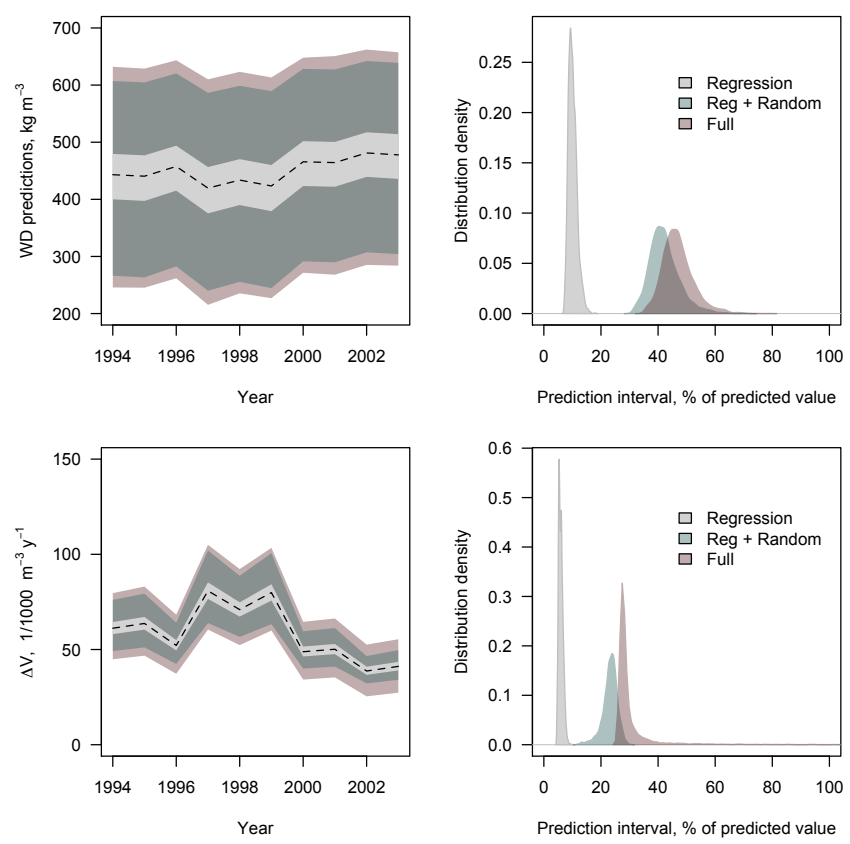

Figure 4. Left, variations of the MCMC annual predictions and prediction intervals $(95 \%)$ of wood density and volume increment for one given tree, randomly chosen while accounting for different error sources: regression only/regression and random effects/regression, random effects and residual variance; right, distribution density of the relative prediction interval (expressed in percentage of the prediction) for all trees included in the simulation, according to the error sources included.

always smaller than predictions based on a constant density (Fig. 5). The prediction uncertainty was considerably higher when accounting for random effects on either the WD or the volume increment. The full error propagation ( $\mathrm{sc} 4)$ had a relative prediction uncertainty up to $60 \%$ of the predicted value on average, occasionally reaching or overcoming $100 \%$. Constant density predictions had logically the lowest uncertainties (less than $10 \%$ ) since they only included the error from the volume increment estimation. Wood density had the greatest contribution to the prediction uncertainty, and mainly through the between-tree variations. The parametric estimation (sc3) had a prediction interval 4 times lower than the full error propagation prediction (sc4), showing an underestimation of the error made by considering the uncertainty related to the regression coefficients only.

\subsubsection{At plot level}

At plot level, which is the aggregation of the tree-level predictions and errors, the prediction errors tended to compensate each other since the relative prediction intervals of the annual biomass production were smaller than at tree-level (Fig. 6). Thus the interval of biomass production estimates varied from $\sim 7 \%$ (sc1: no random effect, no residual error) to $10-30 \%$ (sc4: full error propagation) at stand level. It is noticeable that the relative prediction interval at $95 \%$ was never greater than $40 \%$ despite the combined errors of the two models (wood density and volume increment) plus the errors related to the random tree-level variations.

The variation between years in the prediction error was also very low (Fig. 6) despite contrasted ring widths. The error of the predictions based on regression errors only ( $\mathrm{sc} 1$ and sc3) did not vary with increasing number of trees in the plot (Fig. 6). In contrast, the predictions error decreased slightly with increasing number of trees for the scenarios that used a (tree-level) random-effect term (sc2 and sc4).

\section{Discussion}

\subsection{Overestimations of the variations in annual biomass increment under constant density}

Wood density was found to decrease when ring width increased, in agreement with previous studies on Norway spruce (e.g. Lindström, 1996; Dutilleul et al., 1998). Despite the seemingly high correlation between ring width and WD, the decrease of WD was not enough to compensate the increase in ring width but contributed to attenuate its effects. The order of magnitude of the WD variability was not - and by far - as large as that of ring width. Hence, it is logical to find a moderate compensation between radial growth and wood density variations even in extreme years such as 1976: $15 \%$ at plot level. Nevertheless, when the focus is put on key years, such as years of climatic extremes, the measurements of WD is necessary to avoid a systematic underestimation of the biomass increment or carbon uptake. Climate is indeed probably the most important driver of WD variations with influences at both inter- and intra-annual time steps (e.g. Gindl et al., 2000; Bouriaud et al., 2005). These results are consistent with those reported in Babst et al. (2014a) showing that accounting for the variations in WD strongly improved the match between the tree-ring-based above-ground wood biomass increment estimations and the seasonal $\mathrm{CO}_{2}$ fluxes measured by eddy covariance.

A constant value of wood density, such as that implicitly used in biomass equations, can generate systematic deviations because it only has a few chances to be equal to the mean density of the trees to which the model is applied. Even if a site-specific WD value is used, neglecting the radial increment of WD (i.e. the age-related trend) will also lead to an underestimation of the biomass increment. This source of error can unfortunately not be compensated by a larger sampling since it affects all the trees simultaneously. This has consequences not only for the annual productivity estimations but also for periodical productivity assessments, such as those conducted on permanent sample plots over a 5- or 10-year period.

Compensation of increased growth rate by a decrease in wood density was documented for Norway spruce but over a 

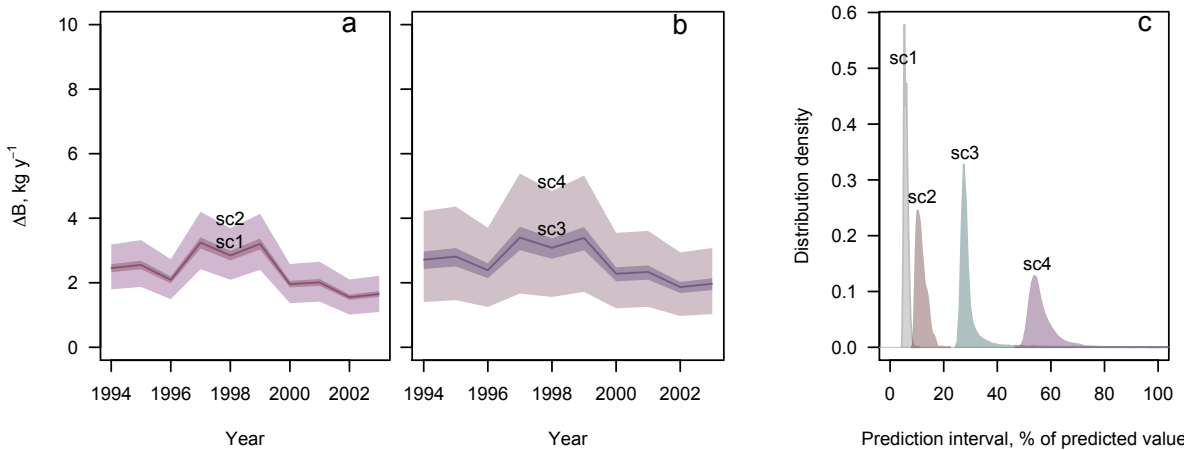

Figure 5. Annual biomass increment (posterior MCMC distribution) for one given tree chosen as representative with its associated prediction error for scenario 1 and 2 (a) or scenario 3 and 4 (b); (c) distribution density of relative prediction interval (expressed in percent of the prediction) for all trees included in the simulation, according to the scenario. Scenario 1 is based on constant WD and no random or residual error from the volume increment model, scenario 2 is based on constant WD and random error in the volume increment model, scenario 3 is based on modelled WD but without random and residual error accounting, and scenario 4 is based on modelled WD and volume increment, accounting for all error sources (see Sect. 2.3 for more details).
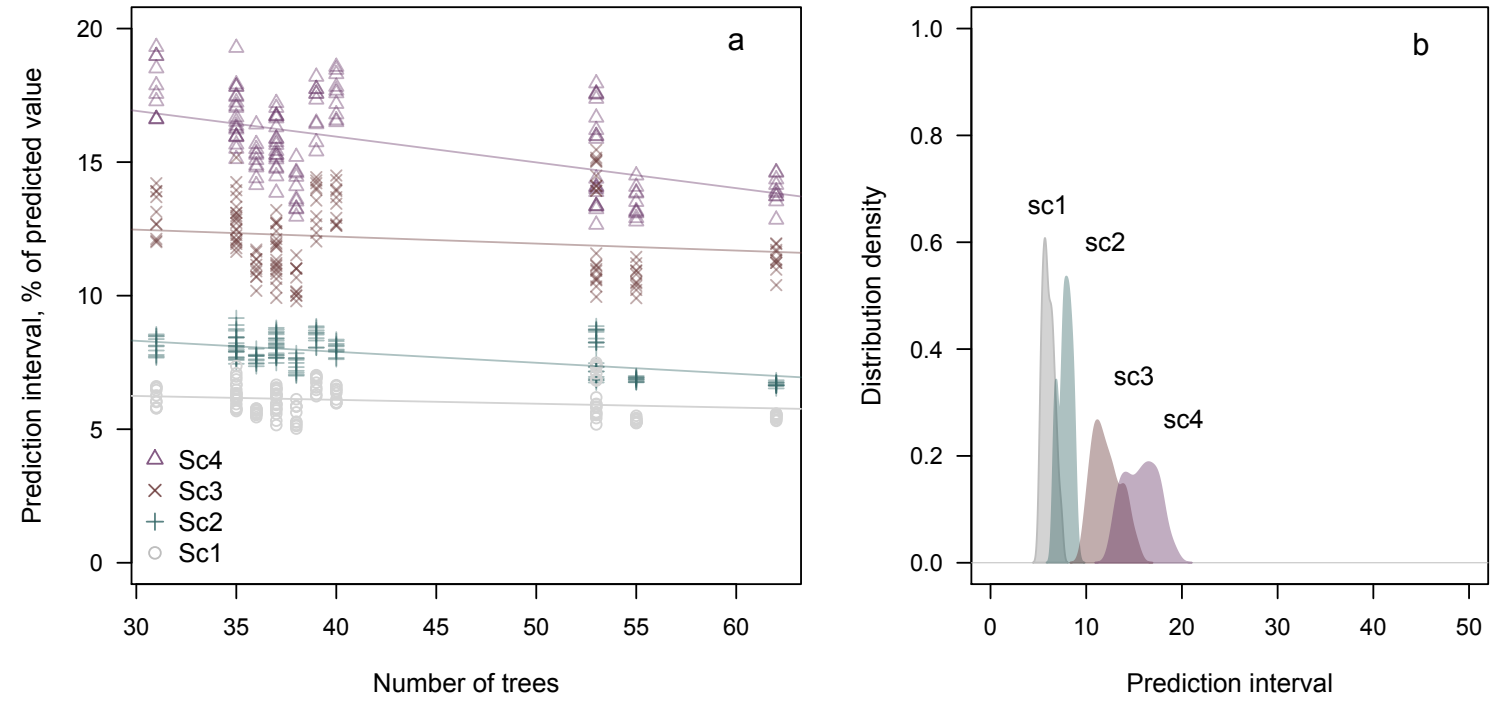

Figure 6. Plot-level annual relative prediction intervals of the biomass increment as a function of the number of trees sampled in the plot for the four scenarios (a). Distribution density of the relative prediction interval of the biomass increment at plot level, all plots pooled (b).

long timescale (Bontemps et al., 2013). The trends in radial growth and in WD reported for many species could lead to such deviations between the actual WD and the modelled or implicit WD. In this context, a local calibration would reduce such errors but cannot solve the problem of the variations between years and between trees.

The anticorrelation between ring width and wood density seems to be a general feature in Norway spruce according to the literature (e.g. Lindström, 1996; Dutilleul et al., 1998) but the phenomenon is not limited to this species (Babst et al., 2014a). The attenuation therefore probably occurs at a large scale. The between-tree variability in the relationship has also been reported in several studies and probably is a widespread feature with potentially large consequences on the error of annual biomass increment predictions, as demon- strated by this study. The fact that the trees used to assess both the wood density variations and to model the volume increment came from the same site as those used for the error estimations has ruled out the issues of using locally inappropriate models. Additional errors should be considered in practice when using models that may not be locally valid.

\subsection{Prediction uncertainty}

The inventory-based or tree-ring-based estimations of annual biomass production or carbon uptake are often used for comparisons against other methods such as remote sensing, vegetation models or eddy covariance (Beck et al., 2011; Bunn et al., 2013; Babst et al., 2014a). To be conclusive, the benchmarking however supposes that prediction errors are known 
or can be estimated. High prediction errors would invalidate the biometric approaches but the errors are not always accounted for. Analytical solutions are indeed not always available to estimate the errors of the allometric models, and their estimation remains very complex or based on assumptions. In the case of the biomass increment, the error results from the combination of several models, and the estimation is even more challenging. The use of the MCMC framework here avoids the cumbersome analytical approximations for prediction variances (e.g. Wutzler et al., 2008).

The prediction interval at plot level was on average between 20 and $40 \%$ of the predicted biomass increment value. The uncertainty related to the regression parameters was only about $10 \%$ for both models. Reduced variance may be inherent to the use of local trees and the Bayesian modelling method (Zapata-Cuartas et al., 2012) but these values are similar to those found by Nickless et al. (2011) for biomass estimations following a parametric approach - as opposed to the MCMC method used here. Unlike our results, this study did not however include the random tree-level variations, which appeared to be quite an important source of uncertainty. Indeed, accounting for random tree-level variations in the relation between wood density and ring width increased the prediction interval of the tree-level biomass increment drastically (i.e. decreased the prediction confidence), by a factor of 5. Further errors related to the residual non-explained variance, were, in comparison, very small. Consequently, the prediction interval of the biomass annual increment at plot level increased twofold by accounting for the random-tree effects. Hence, the contribution of WD to the prediction error of the biomass increment was much larger than that of the volume increment model.

The tree-level prediction error (in percentage of the prediction value) was found to be greater the error at plot level. Thus, compensation occurred at plot level when summing up trees predictions. We speculate that this compensation happens because the variations are centred by construction around zero and have both negative and positive values. This explains also why the mean prediction values were always unaffected by accounting for random effects. Hence, neglecting random effects affected the prediction interval more than the predictions themselves.

\subsection{Variations between trees}

The relation between wood density, ring width, and cambial age were proven to fluctuate between trees sampled within a same stand for many species: oak (Guilley et al., 2004; Bergès et al., 2008), common beech (Bouriaud et al., 2004), Norway spruce (Mäkinen et al., 2002; Jaakola et al., 2005; Franceschini et al., 2010). For a given radial growth rate, the trees are building more or less biomass and so storing more or less carbon, according to the density of the wood.

This fluctuation is considered random because it cannot be attributed to a measurable factor. Random tree-level vari- ations were nevertheless reported as a major source of wood density variation in a population (Zhang et al., 1994; Guilley et al., 2004; Bouriaud et al., 2004; Jaakola et al., 2005). It is often hypothesized to be related to genetics, although this is not proven. Provenance studies have brought some insight on it (Hylen, 1999; Rozenberg et al., 2004), but much of the determinism remains unknown. Other factors, such as crown development (Lindström, 1996), could also be invoked to explain this variation source in wood density.

The changes in silvicultural practices, whereby the focus is put on targeted individuals, further stress the importance of errors in tree-level estimations of biomass and biomass increments. The tree-level variations were the largest error source and showed that the inter-tree variations can be seen as a limitation to the tree-level biomass prediction. Despite the many evidences of tree-level random effects, this variation source was largely ignored. Our study proved that the between-tree variations in the relation between ring width and wood density - although within the same species - contributed the most to the uncertainty in the biomass increment predictions. The variations are hypothesized to follow a normal distribution (Lindström and Bates, 1990). Thus, at plot level, compensation is likely to occur. But this situation may not be true for all samples, and certain designs could generate additional biases in the biomass production estimations. In this study, all the trees in a plot were sampled. Other samples, for instance the selection of the biggest trees in a plot as classically done in dendrochronology, could lead to serious deviations as it could involve sampling faster-growing trees. Apart from the bias in productivity caused by a sample focusing on faster-growing trees (Nehrbass-Ahles et al., 2014), the productivity at stand level would probably generate an overestimation related to a decreased wood density as trees producing larger rings would be sampled. Another issue in using the tree-ring parameters (width and density) to produce annual productivity estimations is the presence of autocorrelation or carry-over effects in the series, which are reflected in the derived productivity estimations but are generally not observed in the measured or modelled carbon fluxes (Babst et al., 2014a, b; Rammig et al., 2015).

\subsection{Modelling wood density for biomass increment}

Apart from the climate, the two most-used variables used in modelling annual WD variations are ring width and ring (cambial) age. The relation between WD and radial growth was strong in our study and probably dominant in Norway spruce but may not be so for other species. In beech, for example, the relation between ring width and WD was shown to be weak (Bouriaud et al., 2004) and there was no clear trend in WD related to the age either. Several studies reported a lack of significant correlations between ring width and WD for Norway spruce (e.g. Dutilleul et al., 1998). The relative stability in annual WD values is not calling for a correction of the biomass increment in such situation. It is probable that 
variations in WD would affect the estimation of biomass increment in species for which a relationship with ring width was already observed such oaks (Zhang et al., 1993; Bergès et al., 2008) or larch (Karlman et al., 2005). The contribution to the error in the prediction of biomass production is however likely to be important.

Conversely to ring width, ring age was found to be only slightly influent on the annual wood density in Norway spruce. Ring age is often considered in density models for representing the age trend or for the variations observed near the pith - the juvenile versus mature wood transition (e.g. Franceschini et al., 2010). WD in Norway spruce has been shown to present an age-dependent trend from pith to bark (Dutilleul et al., 1998; Hylen, 1999; Mäkinen et al., 2002), apart from the juvenile wood effect. In our study, the juvenile effect was not included for simplicity (series were pruned to exclude the first 3 years) but also because rings near pith anyway are often missing when working with increment cores. Part of the age effect can be absorbed by the irregular ringwidth variations exhibited by trees growing in stands where thinnings induce successive episodes of growth surge.

Wood density should not be mistaken for stem-specific gravity (Williamson et al., 2010). Bark has a different mass to volume ratio than wood. The contribution of bark to the annual increment is however negligible. The calculated approximation confirms that the variations in specific gravity are proportional to that of wood density. Variations in ring width and WD at upper stem positions were however documented for different species (Bouriaud et al., 2005; Repola, 2006; van der Maaten-Theunissen and Bouriaud, 2012). These variations were mostly in the sense of a lesser reduction in growth of upper stem parts during years of limited growth. Altogether with the WD density effect, these effects show that the reaction of trees to unfavourable climate conditions is exacerbated or overestimated by the breast-height radial growth.

\section{Conclusions}

Annual variations in wood density were proved to compensate partially (up to $15 \%$ ) to the variations in radial growth. Ignoring the relation between ring width and wood density would result in an underestimation of the biomass production in bad years. The use of allometric equations generated estimations with large prediction intervals at tree level, up to $60 \%$, but the prediction errors at plot level compensated for each other. Most of the error in the prediction of a tree's annual biomass increment comes from the great between-tree variability in wood density. Plot-level errors were found to range between 10 and $20 \%$ only. This study validates the approach based on historical diameter records for estimating tree annual biomass increment and stand annual biomass production, but a local calibration of the allometric models reduces the prediction errors considerably. The Supplement related to this article is available online
at doi:10.5194/bg-12-6205-2015-supplement.

Acknowledgements. This work was supported by a grant of the Romanian National Authority for Scientific Research, CNCSUEFISCDI, project number PN-II-ID-PCE-2011-3-0781. C. Wirth is thankful to Sebastian Weist and Ulrich Pruschitzki for help in the field and Anja Kahl for dendrochronological analysis. C. Wirth acknowledges the support of the Max-Planck Society. A. V. Kirdyanov acknowledges EU COST Action FP1106 STReESS. Ernst-Detlef Schulze and Reiner Zimmermann established the Wetzstein site.

Edited by: J. Schöngart

\section{References}

Anthoni, P. M., Knohl, A., Rebmann, C., Freibauer, A., Mund, M., Ziegler, W., Kolle, O., and Schulze, E.D.: Forest and agricultural land use dependent $\mathrm{CO}_{2}$ exchange in Thuringia, Germany, Glob. Change Biol., 10, 2005-2019, 2004.

Babst, F., Poulter, B., Trouet, V., Tan, K., Neuwirth, B., Wilson, R., Carrer, M., Grabner, M., Tegel, W., Levanic, T., Panayotov, M., Urbinati, M., Bouriaud, O., Ciais, P., and Frank, D.: Siteand species-specific responses of forest growth to climate across the European continent, Glob. Ecol. Biogeogr., 22, 706-717, doi:10.1111/geb.12023, 2013.

Babst, F., Bouriaud, O., Papale, D., Gielen, B., Janssens, I.A., Nikinmaa, E., Ibrom, A., Wu, K., Bernhofer, C., Köstner, B., Grünwald, T., and Frank, D.: Above-ground woody carbon sequestration measured from tree rings is coherent with net ecosystem productivity at five eddy-covariance sites, New Phytol., 201, 1289-1303, doi:10.1111/nph.12589, 2014a.

Babst, F., Alexander, M. R., Szejner, P., Bouriaud, O., Klesse, S., Roden, J., Ciais, P., Poulter, B., Frank, D., Moore, J. P., and Trouet, V.: A tree-ring perspective on the terrestrial carbon cycle, Oecologia, 176, 307-322, 2014b.

Barford, C. C., Wofsy, S. C., Goulden, M. L., Munger, J. W., Pyle, E. H., Urbanski, S. P., Hutyra L., Saleska S. R., Fitzjarrald D., and Moore, K.: Factors controlling long-and short-term sequestration of atmospheric $\mathrm{CO}_{2}$ in a mid-latitude forest, Science, 294, 16881691, 2001.

Beck, P. S. A., Juday, G. P., Alix, C., Barber, V. A., Winslow, S. E., Sousa, E. E., Heiser, P., Herriges, J. D., and Goetz, S. J.: Changes in forest productivity across Alaska consistent with biome shift, Ecol. Lett., 14, 373-379, 2011.

Beer, C., Reichstein, M., Tomelleri, E., Ciais, P., Jung, M., Carvalhais, N., Rödenbeck, C., Arain, M. A., Baldocchi, D., Bonan, G. B., Bondeau, A., Cescatti, A., Lasslop, G., Lindroth, A., Lomas, M., Luyssaert, S., Margolis, H., Oleson, K. W., Roupsard, O., Veenendaal, E., Viovy, N., Williams, C., Woodward, F. I., and Papale, D.: Terrestrial gross carbon dioxide uptake: global distribution and covariation with climate, Science, 329, 834-838, 2010 . 
Bergès, L., Nepveu, G., and Franc, A.: Effects of ecological factors on radial growth and wood density components of sessile oak (Quercus petraea Liebl.) in Northern France, Forest Ecol. Manage., 255, 567-579, 2008.

Bergqvist, G.: Wood density traits in Norway spruce understorey: effects of growth rate and birch shelterwood density, Ann. Sci. For., 55, 809-821, 1998.

Bontemps, J. D., Gelhaye, P., Nepveu, G., and Hervé, J. C.: When tree rings behave like foam: moderate historical decrease in the mean ring density of common beech paralleling a strong historical growth increase, Ann. Sci. For., 70, 1-15, 2013.

Bouriaud, O., Breda, N., Le Moguedec, G., and Nepveu, G.: Modelling variability of wood density in beech as affected by ring age, radial growth and climate, Trees-Struct. Func., 18, 264-276, 2004.

Bouriaud, O., Leban, J.M., Bert, D., and Deleuze, C.: Intra-annual variations in climate influence growth and wood density of Norway spruce, Tree Physiol., 25, 651-660, 2005.

Bunn, A. G., Hughes, M. K., Kirdyanov, A. V., Losleben, M., Shishov, V. V., Berner, L. T., Oltchev, A., and Vaganov, E. A.: Comparing forest measurements from tree rings and a spacebased index of vegetation activity in Siberia, Environ. Res. Lett. 8, 035034, doi:10.1088/1748-9326/8/3/035034, 2013.

Ciais, P., Reichstein, M., Viovy, N., Granier, A., Oeìe, J., Allard, V., Aubinet, M., Buchmann, N., Bernhofer, C., and Carrara, A.: Europe-wide reduction in primary productivity caused by the heat and drought in 2003, Nature, 437, 529-533, 2005.

Ciais, P, Schelhaas, M. J., Zaehle, S., Piao, S. L., Cescatti, A., Liski, J., Luyssaert, S., Le-Maire, G., Schulze, E.-D., Bouriaud, O., Freibauer, A., Valentini R., and Nabuurs, G. J.: Carbon accumulation in European forests. Nat. Geosci., 1, 425-429, doi:10.1038/ngeo233, 2008.

Curtis, P., Hanson, P., Bolstad, P., Barford, C., Randolph, J., Schmid, H., and Wilson, K.: Biometric and eddy-covariance based estimates of annual carbon storage in five eastern North American deciduous forests, Agr. Forest Meteorol., 113, 3-19, 2002.

Dutilleul, P., Herman, M., and Avella-Shaw, T.: Growth rate effects on correlations among ring width, wood density, and mean tracheid length in Norway spruce (Picea abies), Can. J. Forest Res., 28, 56-68, 1998.

Evans, R.: Rapid Measurement of the Transverse Dimensions of Tracheids in Radial Wood Sections from Pinus Radiata, Holzforschung, 48, 168-172, 1994.

Franceschini, T., Bontemps, J. D., Gelhaye, P., Rittie, D., Herve, J. C., Gegout, J. C., and Leban, J. M.: Decreasing trend and fluctuations in the mean ring density of Norway spruce through the twentieth century, Ann. For. Sci., 67, 816, doi:10.1051/forest/2010055, 2010.

Franceschini, T., Longuetaud, F., Bontemps, J. D., Bouriaud, O., Caritey, B. D., and Leban, J. M.: Effect of ring width, cambial age, and climatic variables on the within-ring wood density profile of Norway spruce Picea abies (L.) Karst., Trees-Struct. Func., 27, 913-925, 2013.

Gindl, W., Grabner, M., and Wimmer, R.: The influence of temperature on latewood lignin content in treeline Norway spruce compared with maximum density and ring width, Trees-Struct. Func., 14, 409-414, 2000.
Gough, C., Vogel, C., Schmid, H., and Curtis, P.: Controls on annual forest carbon storage: Lessons from the past and predictions for the future, Bioscience, 58, 609-622, 2008.

Guilley, E., Hervé, J. C., and Nepveu, G.: The influence of site quality, silviculture and region on wood density mixed model in Quercus petraea Liebl, Forest Ecol. Manage., 189, 111-121, 2004.

Hylen, G.: Age trends in genetic parameters of wood density in young Norway spruce, Can. J. Forest Res., 29, 135-143, 1999.

Ilvesniemi, H., Levula, J., Ojansuu, R., Kolari, P., Kulmala, L., Pumpanen, J., Launiainen, S., Vesala, T., and Nikinmaa, E.: Long-term measurements of the carbon balance of a boreal Scots pine dominated forest ecosystem, Bor. Environ. Res., 14, 731753, 2009.

Jaakkola, T., Mäkinen, H., and Saranpää, P.: Wood density in Norway spruce: changes with thinning intensity and tree age, Can. J. Forest Res., 35, 1767-1778, 2005.

Jyske, T., Makinen, H., and Saranpaa, P.: Wood density within Norway spruce stems, Silva Fenn., 42, 439-455, 2008.

Karlman, L., Mörling, T., and Martinsson, O.: Wood density, annual ring width and latewood content in larch and Scots pine, Eurasian J. Forest Res., 8, 91-96, 2005.

Lindström, H.: Basic density of Norway spruce. Part II. Predicted by stem taper, mean growth ring width, and factors related to crown development, Wood Fiber Sci., 28, 240-251, 1996.

Lindström, M. J. and Bates, D. M.: Nonlinear mixed effects models for repeated measures data, Biometrics, 673-687, 1990.

Lundgren, C.: Microfibril angle and density patterns of fertilized and irrigated Norway spruce, Silva Fenn., 38, 107-117, 2004.

Mäkinen, H., Saranpää, P., and Linder, S.: Wood-density variation of Norway spruce in relation to nutrient optimization and fibre dimensions, Can. J. Forest Res., 32, 185-194, 2002.

Molto, Q., Rossi, V., and Blanc, L.: Error propagation in biomass estimation in tropical forests. Methods Ecol. Evol., 4, 175-183, doi:10.1111/j.2041-210x.2012.00266.x, 2013.

Nehrbass-Ahles, C., Babst, F., Klesse, S., Nötzli, M., Bouriaud, O., Neukom, R., Dobbertin, M., and Frank, D.: The influence of sampling design on tree-ring based quantification of forest growth, Glob. Change Biol., 20, 2867-2885, 2014.

Nickless, A., Scholes, R. J., and Archibald, S.: Calculating the variance and prediction intervals for estimates obtained from allometric relationships, S. Afr. J. Sci., 107, 356, doi:10.4102/sajs.v107i5/6.356, 2011

Ohtsuka, T., Mo, W., Satomura, T., Inatomi, M., and Koizumi, H.: Biometric based carbon flux measurements and net ecosystem production (NEP) in a temperate deciduous broad-leaved forest beneath a flux tower, Ecosystems, 10, 324-334, 2007.

Pinheiro, J., Bates, D., DebRoy, S., and Sarkar, D.: R Development Core Team (2011) nlme: linear and nonlinear mixed effects models, R package version 3.1-98, R Foundation for Statistical Computing, Vienna, 2011.

Rammig, A., Wiedermann, M., Donges, J. F., Babst, F., von Bloh, W., Frank, D., Thonicke, K., and Mahecha, M. D.: Coincidences of climate extremes and anomalous vegetation responses: comparing tree ring patterns to simulated productivity, Biogeosciences, 12, 373-385, doi:10.5194/bg-12-373-2015, 2015.

R Development Core team: R: a language and environment for statistical computing, R Foundation for Statistical Computing, Vienna, Austria, 2014. 
Reichstein, M., Ciais, P., Papale, D., Valentini, R., Running, S., Viovy, N., Cramer, W., Granier, A., Ogee, J., Allard, V., Aubinet, M., Bernhofer, C., Buchmann, N., Carrara, A., Grünwald, T., Heimann, M., Heinesch, B., Knohl, A., Kutsch, W., Loustau, D., Manca, G., Matteucci, G., Miglietta, F., Ourcival, J. M., Pilegaard, K., Pumpanen, J., Rambal, S., Schaphoff, S., Seufert, G., Soussana, J. F., Sanz, M. J., Vesala, T., and Zhao, M.: Reduction of ecosystem productivity and respiration during the European summer 2003 climate anomaly: a joint flux tower, remote sensing and modelling analysis, Glob. Change Biol., 13, 634-651, doi:10.1111/j.1365-2486.2006.01224.x, 2007.

Repola, J.: Models for vertical wood density of Scots pine, Norway spruce and birch stems, and their application to determine average wood density, Silva Fenn., 40, 673-685, 2006.

Rey, A. N. A. and Jarvis, P.: Modelling the effect of temperature on carbon mineralization rates across a network of European forest sites (FORCAST), Glob. Change Biol., 12, 1894-1908, 2006.

Richardson, A. D., Black, T. A., Ciais, P., Delbart, N., Friedl, M. A., Gobron, N., Hollinger, D. Y., Kutsch, W. L., Longdoz, B., and Luyssaert, S.: Influence of spring and autumn phenological transitions on forest ecosystem productivity, Philos. T. R. Soc. B, 365, 3227-3246, 2010.

Rocha, A., Goulden, M., Dunn, A., and Wofsy, S.: On linking interannual tree ring variability with observations of whole-forest $\mathrm{CO}_{2}$ flux, Glob. Change Biol., 12, 1378-1389, 2006.

Rozenberg, P., Schüte, G., Ivkovich, M., Bastien, C., and Bastien, J.C.: Clonal variation of indirect cambium reaction to withingrowing season temperature changes in Douglas-fir, Forestry, 77, 257-268, 2004.

Spiegelhalter, D. J., Thomas, A., Best, N., and Lunn, D.: WinBugs 1.4, Cambridge, UK: MRC Biostatistics Unit, Cambridge University, 2003.

Schweingruber, F. H.: Tree rings: basics and applications of dendrochronology, Kluwer Academic Publishers, 276 pp., 1988.

van der Maaten-Theunissen, M. and Bouriaud, O.: Climate-growth relationships at different stem heights in silver fir and Norway spruce, Can. J. Forest Res., 42, 958-969, 2012.
Vilà, M., Carrillo-Gavilán A., Vayreda J., Bugmann H., Fridman J., Grodzki W., Haase J., Kunstler G., Schelhaas M. J., and Trasobares A.: Disentangling Biodiversity and Climatic Determinants of Wood Production. PloS One, 8, e53530, doi:10.1371/journal.pone.0053530, 2013.

Wilhelmsson, L., Arlinger, J., Spångberg, K., Lundqvist, S. O., Grahn, T., Hedenberg, Ö., and Olsson, L.: Models for predicting wood properties in stems of Picea abies and Pinus sylvestris in Sweden, Scand. J. Forest Res., 17, 330-350, 2002.

Williamson, G. B. and Wiemann, M. C.: Measuring wood specific gravity correctly. Am. J. Bot., 97, 519-524, 2010.

Wirth, C., Schumacher, J., and Schulze, E. D.: Generic biomass functions for Norway spruce in Central Europe - a meta-analysis approach toward prediction and uncertainty estimation, Tree Physiol., 24, 121-139, 2004.

Wu, X., Babst, F., Ciais, P., Frank, D., Reichstein, M., Wattenbach, M., Zang, C., and Mahecha, M. D.: Climate-mediated spatiotemporal variability in terrestrial productivity across Europe, Biogeosciences, 11, 3057-3068, doi:10.5194/bg-11-3057-2014, 2014.

Wutzler, T., Wirth, C., and Schumacher, J.: Generic biomass functions for Common beech (Fagus sylvatica) in Central Europe: predictions and components of uncertainty, Can. J. Forest Res., 38, 1661-1675, 2008.

Zapata-Cuartas, M., Sierra, C. A., and Alleman, L.: Probability distribution of allometric coefficients and Bayesian estimation of aboveground tree biomass, Forest Ecol. Manage., 277, 173-179, 2012.

Zhang, S. Y., Owoundi, R. E., Nepveu, G., Mothe, F., and Dhôte, J.F.: Modelling wood density in European oak (Quercus petraea and Quercus robur) and simulating the silvicultural influence, Can. J. Forest Res., 23, 2587-2593, 1993.

Zhang, S. Y., Nepveu, G., and Owoundi, R. E.: Intratree and intertree variation in selected wood quality characteristics of European oak (Quercus petraea and Quercus robur), Can. J. Forest Res., 24, 1818-1823, 1994. 